\title{
Virulence Factors of Staphylococcus aureus Isolated from Korean Pork bulgogi: Enterotoxin Production and Antimicrobial Resistance
}

\author{
Byeong Su Jung ${ }^{1}$, Yong Ju Lee ${ }^{1}$, Na-Kyoung Lee ${ }^{1}$, Hyoun Wook Kim², \\ Mi-Hwa Oh ${ }^{2}$, and Hyun-Dong Paik ${ }^{1,3, *}$ \\ ${ }^{1}$ Department of Food Science and Biotechnology of Animal Resources, Konkuk University, Seoul 143-701, Korea \\ ${ }^{2}$ Animal Products and Development division, National Institute of Animal Science, RDA, Suwon 441-706, Korea \\ ${ }^{3}$ Bio/Molecular Informatics Center, Konkuk University, Seoul 143-701, Korea
}

\begin{abstract}
The aim of this study was to investigate the antimicrobial resistance profiles of and the enterotoxin gene distribution in 4 strains of Staphylococcus aureus (S10-2, S10-3, S12-2, and S13-2) isolated from 90 bulgogi samples. The S. aureus enterotoxin H gene (seh) was found in all the strains, while the $S$. aureus enterotoxin A gene (sea) was found only in 3 of the 4 strains. The S10-2 strain expressed a combination of enterotoxin genes - seg, seh, sei, sej, selm, and seln. The strains S10-2 and S13-2 were resistant to ampicillin and penicillin $\mathrm{G}$, and all the isolated strains were resistant to tetracycline. The S10-2 strain was the only mecA-positive strain; it was also resistant to $\beta$-lactam antibiotics. Thus, genes encoding enterotoxin as well as those conferring antibiotic resistance were identified in the $S$. aureus strains isolated from pork bulgogi. These results represents the potential occurrence of MRSA in pork bulgogi, and the need for a monitoring system for pork bulgogi in order to prevent an outbreak of staphylococcal food poisoning.
\end{abstract}

Keywords: foodborne pathogen, Staphylococcus aureus, enterotoxin, antibiotic susceptibility

Received June 15, 2015; Revised July 20, 2015; Accepted July 20, 2015

\section{Introduction}

Staphylococcus aureus is one of the most common causes of food borne diseases and is found in a variety of foods (Andreja, 2012). S. aureus is a public health concern because of its ability to produce enterotoxins and to survive in harsh conditions. Staphylococcal enterotoxins (SEs) are a leading cause of staphylococcal food poisoning in humans; they may also be involved in other types of infections. The symptoms of SE poisoning are increased saliva secretion, vomiting, abdominal cramping, and diarrhea, with blood in some cases. Staphylococcal enterotoxins A (SEA) through to staphylococcal enterotoxin $\mathrm{E}$ (SEE) are the most commonly isolated enterotoxins in food poisoning outbreaks (Argudín et al., 2010). However, a number of other enterotoxin types designated SEGSEJ, SElM, SE $/ \mathrm{N}$, and SElO has been defined (Argudín et al., 2010; Yarwood et al., 2002).

\footnotetext{
*Corresponding author: Hyun-Dong Paik, Department of Food Science and Biotechnology of Animal Resources, Konkuk University, Seoul 143-701, Korea. Tel: +82-2-2049-6011, Fax: +822-455-3082, E-mail: hdpaik@konkuk.ac.kr
}

The extensive therapeutic use of antibiotics in humans and animals has contributed to the increase in antibiotic resistance in pathogens. Especially problematic among these resistant pathogens are methicillin-resistant $S$. aureus (MRSA), which have become a serious concern due to the high rates of community and nosocomial-acquired infections. In addition, the phenomenon of horizontal gene transfer has resulted in the spread of methicillin resistance, increasing the pressure on a limited supply of alternative antibiotics. Antibiotic resistance in MRSA is determined by the mecA and femA genes (Keun et al., 2011). The mecA gene encodes a penicillin binding protein (PBP$2 a)$, which has a low binding affinity for methicillin and other $\beta$-lactam antibiotics.

Pork bulgogi is barbecued or pan-fired pork that has been marinated with a mixture of soy sauce, sugar, minced garlic, green onion, black pepper, and sesame oil. Its microbial safety was reported their bacterial condition (Ahn et al., 2012; Hong et al., 2011; Jo et al., 2004). Due to the high salt content of soy sauce, bulgogi does not provide an environment suitable for microbial growth (Jo et al, 2004). As a result, just 5 strains were isolated from 90 pork bulgogi samples (Ahn et al., 2012). The low num-

(9)This is an open access article distributed under the terms of the Creative Commons Attribution Non-Commercial License (http://creativecommons.org/licences/ by-nc/4.0) which permits unrestricted non-commercial use, distribution, and reproduction in any medium, provided the original work is properly cited. 
bers of $S$. aureus isolates may be due to soy sauce, which has been shown to exert antimicrobial effects against $S$. aureus, Shigella flexneri, Vibrio cholera, Salmonella Enteritidis, and Escherichia coli (Kataoka, 2005). The aim of this study was to investigate the antimicrobial resistance profiles of and the enterotoxin gene distribution in $S$. aureus strains isolated from pork bulgogi.

\section{Materials and Methods}

\section{Bacterial strains}

The four $S$. aureus strains S10-2, S10-3, S12-2, and S13-2 were isolated from raw pork bulgogi using BairdParker agar plates enriched with egg yolk (EY) tellurite (Ahn et al., 2012). Five different $S$. aureus strains KCCM 11593, ATCC 25923, KCCM 40510, KCCM 40511, and KCCM 40512 were used as standards. Frozen stocks were maintained at $-80^{\circ} \mathrm{C}$ in tryptic soy broth (TSB, Difco
Laboratories, USA) containing 20\% glycerol. The $S$. aureus strains were incubated at $37^{\circ} \mathrm{C}$ for $24 \mathrm{~h}$ in TSB, and used for further study.

\section{S. aureus DNA extraction}

Following overnight growth, the $S$. aureus strains were harvested by centrifugation at $8,900 \times g$ for $15 \mathrm{~min}$. The pelleted cells were used for genomic DNA extraction using the AccuPrep ${ }^{\circledR}$ genomic DNA extraction kit (Bioneer Co., Korea), together with lysozyme treatment (Sigma Chemical Co., USA), according to the manufacturer's instructions.

PCR detection of Staphylococcal enterotoxin genes PCR was used to test for the presence of $23 \mathrm{~S}$ rRNA, $n u c$, and staphylococcal enterotoxin (SE) genes defined (Argudín et al., 2010; Yarwood et al., 2002). The PCR reaction was performed in a $20 \mu \mathrm{L}$ reaction volume containing 10 pmol of each primers (Table 1 ), $25 \mu \mathrm{L}$ of $2 \times$

Table 1. Used oligonucleotide primers and amplification conditions

\begin{tabular}{|c|c|c|c|c|}
\hline Genes & $\begin{array}{l}\text { Primer } \\
\end{array}$ & Oligonucleotide sequences & Product size (bp) & Annealing temp. $\left({ }^{\circ} \mathrm{C}\right)$ \\
\hline \multirow{2}{*}{ 23S rRNA } & STAUR2 & ACGGAGTTACAAAGGACGAC & \multirow{2}{*}{1,250} & \multirow{2}{*}{64} \\
\hline & STAUR4 & AGCTCAGCCTTAACGAGTAC & & \\
\hline \multirow{2}{*}{ nис } & nuc-1 & GCGATTGATGGTGATACGGTT & \multirow{2}{*}{279} & \multirow{2}{*}{55} \\
\hline & nuc-2 & AGCCAAGCCTTGACGAACTAAAGC & & \\
\hline \multirow{2}{*}{ sea } & SEA-1 & AAAGTCCCGATCAATTTATGGCTA & \multirow{2}{*}{219} & \multirow{2}{*}{55} \\
\hline & SEA-2 & GTAATTAACCGAAGGTTCTGTAGA & & \\
\hline \multirow{2}{*}{$s e b$} & SEB-1 & TCGCATCAAACTGACAAACG & \multirow{2}{*}{476} & \multirow{2}{*}{55} \\
\hline & SEB-2 & GCAGGTACTCTATAAGTGCC & & \\
\hline \multirow{2}{*}{$\mathrm{sec}$} & SEC-1 & GACATAAAAGCTAGGAATTT & \multirow{2}{*}{257} & \multirow{2}{*}{55} \\
\hline & SEC-2 & AAATCGGATTAACATTATCC & & \\
\hline \multirow{2}{*}{ sed } & SED-1 & CTAGTTTGGTAATATCTCCT & \multirow{2}{*}{317} & \multirow{2}{*}{55} \\
\hline & SED-2 & TAATGCTATATCTTATAGGG & & \\
\hline \multirow{2}{*}{ see } & SEE-1 & TAGATAAAGTTAAAACAAGC & \multirow{2}{*}{169} & \multirow{2}{*}{55} \\
\hline & SEE-2 & TAACTTACCGTGGACCCTTC & & \\
\hline \multirow{2}{*}{ seg } & SEG-1 & AATTATGTGAATGCTCAACCCGATC & \multirow{2}{*}{642} & \multirow{2}{*}{55} \\
\hline & SEG-2 & AAACTTATATGGAACAAAAGGTACTAGTTC & & \\
\hline \multirow{2}{*}{ seh } & SEH-1 & CAATCACATCATATGCGAAAGCAG & \multirow{2}{*}{376} & \multirow{2}{*}{55} \\
\hline & SEH-2 & CATCTACCCAAACATTAGCACC & & \\
\hline \multirow{2}{*}{ sei } & SEI-1 & CTCAAGGTGATATTGGTGTAGG & \multirow{2}{*}{577} & \multirow{2}{*}{55} \\
\hline & SEI-2 & AAAAAACTTACAGGCAGTCCATCTC & & \\
\hline & SEJ-1 & CATCAGAACTGTTGTTCCGCTAG & 102 & 55 \\
\hline sej & SEJ-2 & CTGAATTTTACCATCAAAGGTAC & 192 & 55 \\
\hline colm & SEM-1 & TCTTAGGAACTATTATGGTAGC & 471 & 55 \\
\hline selm & SEM-2 & CCTGCATTAAATCCAGAA & 471 & 55 \\
\hline soln & SEN-1 & GGAGTTACGATACATGATGG & 207 & 55 \\
\hline seln & SEN-2 & ACTCTGCTCCCACTGAAC & 292 & 55 \\
\hline selo & SEO-1 & TGATGATTATATAAATAATCGATTTACG & 249 & 55 \\
\hline selo & SEO-2 & ATATGTACAGGCAGTATCC & 249 & 55 \\
\hline$m e c \mathrm{~A}$ & mecA-1 & TCACCTTGTCCGTAACCTGA & 678 & \\
\hline mecA & $\operatorname{mec} A-2$ & TCGTGTCACAATCGTTGACG & 678 & 57 \\
\hline & femA-1 & CGAGGTCATTGCAGCTTGCT & & \\
\hline fem $\mathrm{A}$ & femA-2 & CCAGCATTACCTGTAATCTCGCCA & 231 & 57 \\
\hline
\end{tabular}


Go Taq ${ }^{\circledR}$ Green Master Mix (Promega, USA), $2 \mu \mathrm{L}$ of template DNA. The final volume was adjusted to $50 \mu \mathrm{L}$ using RNase free sterile water. All amplification steps were carried out in a thermocycler (Bioer, Switzerland) with an initial denaturation step at $94^{\circ} \mathrm{C}$ for $5 \mathrm{~min}$, followed by 30 cycles of denaturation at $94^{\circ} \mathrm{C}$ for $2 \mathrm{~min}$, annealing at $55-64^{\circ} \mathrm{C}$ for $30 \mathrm{~s}$, and a $30 \mathrm{~s}$ extension at $72^{\circ} \mathrm{C}$, follow by a final extension at $72^{\circ} \mathrm{C}$ for $10 \mathrm{~min}$. The amplified PCR products were resolved by electrophoresis in a $1 \%$ agarose gel.

\section{Antibiotic susceptibility}

Antibiotic susceptibility of the $S$. aureus strains were tested using the disc agar diffusion method on Mueller Hinton agar (Dection Dickinson, France), following the guidelines of the Clinical and Laboratory Standards Institute (CLSI, 2007). The antibiotic discs used were as tetracycline $(30 \mu \mathrm{g})$, streptomycin $(10 \mu \mathrm{g})$, gentamicin $(30 \mu \mathrm{g})$, vancomycin $(30 \mu \mathrm{g})$, amoxicillin $(20 \mu \mathrm{g})$ and clavulanic acid $(10 \mu \mathrm{g})$, ampicillin $(10 \mu \mathrm{g})$, penicillin (10 IU), oxacillin $(10 \mu \mathrm{g})$, cefazolin $(30 \mu \mathrm{g})$, and cephalothin $(30 \mu \mathrm{g})$. The strains were classified as susceptible, intermediate, or resistant according to the supplier's instructions.

\section{Detection of mecA and femA genes}

The mecA and $f e m \mathrm{~A}$ genes primers used as a biomarker for resistance. The FastPCR software program (http://primerdigital.com/fastpcr.hml) was used to analyze primers (Table 1) for self-dimerization, cross-dimerization, and optimum annealing temperature. PCR conditions was followed manufacture's instruction, and annealing temperatures are shown in Table 1.

\section{Results and Discussion}

\section{Detection of enterotoxin genes of the $S$. aureus strains isolated from pork bulgogi}

The $S$. aureus strains were isolated from pork bulgogi using a selective medium in our previous study and were identified as $S$. aureus by Gram staining, catalase testing, latex agglutination, and the API Staph System (Ahn et al., 2012). In this study, the 4 isolates were confirmed as $S$.
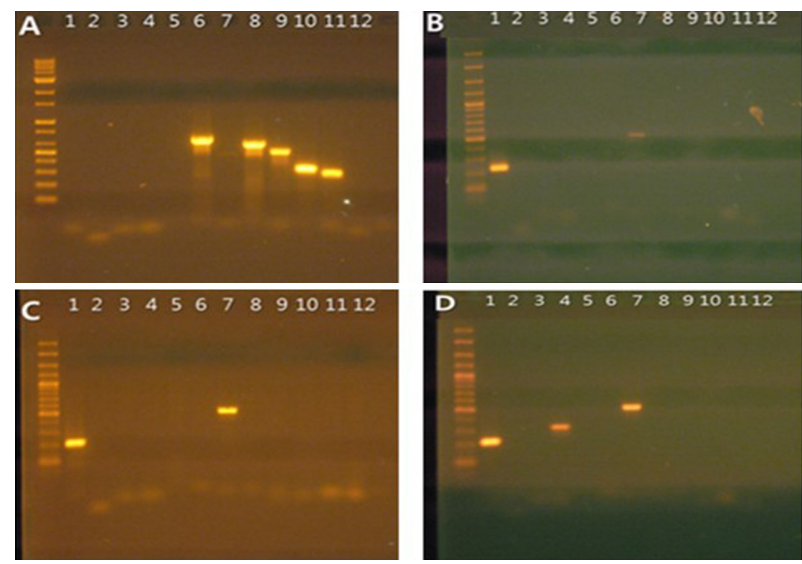

Fig. 1. Agarose gel electrophoresis analysis of PCR products of enterotoxin genes. (A) 10-2, (B) 10-3, (C) 12-2, (D) 13-2. Lane 1, sea; lane 2, seb; lane 3, sec; lane 4, sed; lane 5, see; lane 6, seg; lane 7, seh; lane 8, sei; lane 9, sej; lane 10, selm; lane 11, seln; lane 12, selo.

aureus strains by PCR amplification of the 23S rRNA and $n u c$ genes (Table 2).

Staphylococcal enterotoxins (SEs) belong to a large family of staphylococcal pyrogenic exotoxins, which have been implicated in food poisoning, causing toxic shocklike syndromes, and several allergic and autoimmune diseases (Ortega et al., 2010). Fig. 1 shows the results for the PCR detection of the enterotoxin genes sea to selo. The strain S10-2 possessed 6 enterotoxin genes: seg, seh, sei, sej, selm, and seln. Strains S10-3 and S12-2 possessed the sea and seh enterotoxin genes. The strain S13-2 was shown to possess 3 genes encoding SEA, SED, and SEH. The seh gene, which encodes SEH, was detected in all the strains; however, there was no amplification of the enterotoxin genes seb, sec, see, and selo. Results of enterotoxin genes had a different as the strains. The enterotoxins SEA, SEB, and SED are the most common enterotoxins associated with human food-poisoning outbreaks (Argudín et al., 2010; Zschck et al., 2005). In addition, SEG, SEH, and SEI have also been shown to be emetic after oral administration in a primate model (Argudín et al., 2010).

\section{Antibiotic susceptibility}

$S$. aureus infections are primarily controlled through

Table 2. Characteristics of isolated $S$. aureus strains from pork bulgogi

\begin{tabular}{ccccc}
\hline \hline Isolate & 23S rRNA gene & nuc gene & SE genes & femA gene \\
S10-2 & + & + & seg, seh, sei, sej, selm, seln & + \\
S10-3 & + & + & sea, seh & + \\
S12-2 & + & + & sea, seh & + \\
S13-2 & + & + & sea, sed, seh & + \\
\hline
\end{tabular}


Table 3. Antibiotic resistance of control strains and isolated $S$. aureus from pork bulgogi

\begin{tabular}{|c|c|c|c|c|c|c|c|c|c|c|}
\hline \multirow[b]{2}{*}{ Antibiotic groups } & \multirow[b]{2}{*}{ Antibiotic } & \multicolumn{9}{|c|}{ Strains } \\
\hline & & $\begin{array}{c}\mathrm{KCCM} \\
11593\end{array}$ & $\begin{array}{l}\text { ATCC } \\
25923\end{array}$ & $\begin{array}{c}\text { KCCM } \\
40510\end{array}$ & $\begin{array}{c}\text { KCCM } \\
40511\end{array}$ & $\begin{array}{c}\text { KCCM } \\
40512\end{array}$ & $\mathrm{~S} 10-2$ & S10-3 & $\mathrm{S} 12-2$ & S13-2 \\
\hline Tetracyclines & Tetracycline $(30 \mu \mathrm{g})$ & $\mathrm{S}^{\mathrm{a}}$ & $\mathrm{S}$ & $\mathrm{R}^{\mathrm{b}}$ & $\mathrm{S}$ & $\mathrm{S}$ & $\mathrm{R}$ & $\mathrm{R}$ & $\mathrm{R}$ & $\mathrm{R}$ \\
\hline \multirow{2}{*}{ Aminoglycosides } & Streptomycin $(10 \mu \mathrm{g})$ & $\mathrm{S}$ & $\mathrm{S}$ & $\mathrm{R}$ & S & S & S & S & S & S \\
\hline & Gentamicin $(30 \mu \mathrm{g})$ & $\mathrm{S}$ & $\mathrm{S}$ & $\mathrm{S}$ & $\mathrm{R}$ & $\mathrm{S}$ & S & $\mathrm{S}$ & $\mathrm{S}$ & $\mathrm{S}$ \\
\hline Glycopeptide & Vancomycin $(30 \mu \mathrm{g})$ & $\mathrm{S}$ & $\mathrm{S}$ & $\mathrm{S}$ & S & S & S & S & S & S \\
\hline Amino penicillin & $\begin{array}{c}\text { Amoxicillin }(20 \mu \mathrm{g})+ \\
\text { Clavulanic acid }(10 \mu \mathrm{g})\end{array}$ & $\mathrm{S}$ & $\mathrm{S}$ & $\mathrm{R}$ & $\mathrm{S}$ & $\mathrm{S}$ & S & $\mathrm{S}$ & $\mathrm{S}$ & $\mathrm{S}$ \\
\hline \multirow{3}{*}{$\beta$-Lactam } & Ampicillin $(10 \mu \mathrm{g})$ & $\mathrm{S}$ & $\mathrm{S}$ & $\mathrm{R}$ & $\mathrm{R}$ & $\mathrm{R}$ & $\mathrm{R}$ & S & S & $\mathrm{R}$ \\
\hline & Penicillin (10 IU) & $\mathrm{S}$ & $\mathrm{S}$ & $\mathrm{R}$ & $\mathrm{R}$ & $\mathrm{R}$ & $\mathrm{R}$ & S & S & $\mathrm{R}$ \\
\hline & Oxacillin $(10 \mu \mathrm{g})$ & $\mathrm{S}$ & $\mathrm{S}$ & $\mathrm{R}$ & $\mathrm{R}$ & $\mathrm{R}$ & $\mathrm{R}$ & S & S & $\mathrm{S}$ \\
\hline \multirow{2}{*}{ Cephalosporins } & Cefazoline $(30 \mu \mathrm{g})$ & $\mathrm{S}$ & $\mathrm{S}$ & $\mathrm{R}$ & S & S & S & S & S & $\mathrm{S}$ \\
\hline & Cephalothin $(30 \mu \mathrm{g})$ & $\mathrm{S}$ & $\mathrm{S}$ & $\mathrm{R}$ & S & S & S & S & S & S \\
\hline
\end{tabular}

${ }^{\mathrm{a}}$ Sensitive; ${ }^{\mathrm{b}}$ resistant.

antibiotics. It is therefore concerning how rapidly this organism develops resistance to a large number of antibiotics. Here, we compared the antibiotic resistance of the $S$. aureus strains isolated from pork bulgogi to that of the standard strains (KCCM 11593 and ATCC 25923) and the MRSA strains (KCCM 40510, KCCM 40511, and KCCM 40512) (Table 3). As expected the standard S. aureus strains demonstrated no antibiotic resistance. The KCCM 40510 strain was resistant to tetracycline, streptomycin, amoxicillin and clavulanic acid, ampicillin, penicillin, oxacillin, cefazoline, and cephalothin. The strains KCCM 40511 and KCCM 40512 were resistant to ampicillin, penicillin $\mathrm{G}$, and oxacillin. The $S$. aureus isolates S10-2, S10-3, S12-2, and S13-2 strains were all resistant to tetracycline, whereas the S10-2 and S13-2 strains were resistant to ampicillin and penicillin G. Thus, the resistance profile of the isolated strains was similar to that of the MRSA strains, KCCM 40511 and KCCM 40512. Our findings are also consistent with those of Pereira et al. (2009), who reported that ampicillin and penicillin resistance was frequently founded at a ratio of 70 and $73 \%$, respectively.

\section{Detection of $m e c A$ and $f e m A$ genes}

Table 2 shows results for detection of mecA and femA genes in the S. aureus strains isolated from pork bulgogi. All the tested strains possessed the femA gene. The MRSA strains KCCM 40510 and KCCM 40511 were positive for the mecA gene. Although the mecA gene was not detected in the S. aureus strain KCCM 40512, this strain was resistant to oxacillin. Among the strains isolated from pork bulgogi, only the strain S10-2 possessed the mecA gene; consequently, this strain was identified as a MRSA. Although the mecA gene was not detected in the S13-2 strain, antibiotic susceptibility testing revealed resistance to the $\beta$-lactam antibiotics, ampicillin, and penicillin. This may be due to a modified mecA gene, which was not detected by the primers used in this study. Antibiotic resistance can also be plasmid encoded rather than chromosomal (Lee and Lim, 2002). The MRSA strains isolated from pork bulgogi were resistant to a higher number of antibiotics than the methicillin-sensitive strains were. This is consistent with the finding that MRSA strains generally express genes that confer resistance to multiple antibiotics (Kumar et al., 2011).

The S10-2 and S13-2 strains were both resistant to ampicillin and penicillin G. However, the S10-2 stain expressed 6 enterotoxin genes (seg, seh, sei, sej, selm, and seln), while the S13-2 strain possessed only 3 enterotoxin genes (sea, sed, and seh). These results represents the potential occurrence of MRSA in pork bulgogi, and the need for a monitoring system for pork bulgogi in order to prevent an outbreak of staphylococcal food poisoning.

\section{Acknowledgements}

This work was supported by Priority Research Centers Program through the National Research Foundation of Korea (NRF) funded by the Ministry of Education, Science and Technology (2009-0093824).

\section{References}

1. Ahn, S. H., Lee, Y. J., Lee, J. Y., and Paik, H. D. (2012) Microbiological investigation of ready-to-cook pork bulgogi on Korean market. Korean J. Food Sci. An. 32, 441-447.

2. Andreja, R. (2012) Incidence, growth and enterotoxin production of Staphylococcus aureus in insufficiently dried traditional beef ham "govedja prsuta" under different storage conditions. Food Control 27, 369-373. 
3. Argudín, M. A., Mendoza, M. C., and Rodicio, M. R. (2010) Food poisoning and Staphylococcus aureus enterotoxins. Toxins 2, 1751-1773.

4. Clinical Laboratory Standard Institute (CLSI) (2007) Performance Standards for Antimicrobial Susceptibility Testing; Seventeenth Informational Supplement. CLSI document M100S17. Wayne, PA.

5. Hong, J. H., Yoon, E. K., Chung, S. J., Chung, L. S., Cha, M., O'Mahony, M., Vickers, Z., and Kim, K. O. (2011) Sensory characteristics and cross-cultural consumer acceptability of bulgogi (Korean traditional barbecued beef). J. Food Sci. 76, S306-S313.

6. Jo, C., Lee, N. Y., Kang, H. J., Shin, D. H., and Byun, M. W. (2004) Inactivation of foodborne pathogens in marinated beef rib by ionizing radiation. Food Microbiol. 21, 543-548.

7. Kataoka, S. (2005) Functional effects of Japanese style fermented soy sauce (shoyu) and its components. J. Biosci. Bioeng. 100, 227-234.

8. Keun, S. B., Gwang, S. K., Han, N. C., Seong, C. P., Eun, C. K., Hyung, R. K., and Chi, N. S. (2011) Toxins and antibiotic resistance of methicillin-resistant Staphylococcus aureus isolated from clinical specimens. J. Life Sci. 21, 257-264.

9. Kumar, R., Yadav, B. R., and Singh, R. S. (2011) Antibiotic resistance and pathogenicity factors in Staphylococcus aureus isolated from mastitic Sahiwal cattle. J. Biosci. 36, 175-188.

10. Lee, H. S. and Lim, H. (2002) Evaluation of various methods for detection of methicillin-resistance Staphylococcus aureus (MRSA). Korean J. Clin. Microbiol. 5, 105-110.

11. Ortega, E., Abriouel, H., Lucas, R., and Glvez, A. (2010) Multiple roles of Staphylococcus aureus enterotoxins: Pathogenic activity, and correlation to antibiotic resistance. Toxins 2, 2177-2131.

12. Pereira, V., Lopes, C., Castro, A., Silva, J., Gibbs, P., and Teixeira, P. (2009) Characterization for enterotoxin production, virulence factors, and antibiotic susceptibility of Staphylococcus aureus isolates from various foods in Portugal. Food Microbiol. 26, 278-282.

13. Yarwood, J. M., Mccormick, J. K., Paustian, M. L., Orwin, P. M., Kapur, V., and Schlievert, P. M. (2002) Characterization and expression analysis of Staphylococcus aureus pathogenicity island 3. Implications for the evolution of staphylococcal pathogenicity islands. J. Biol. Chem. 277, 13138-13147.

14. Zschck, M., Kloppert, B., Wolter, W., Hamann, H. P., and Lämmler, C. (2005) Pattern of enterotoxin genes seg, seh, sei, and sej positive Staphylococcus aureus isolated from bovine mastitis. Vet. Microbiol. 108, 243-249. 